\title{
Long anterior anal fistula with an external opening in the medial raphe of the scrotum is likely to open radially inside the anal canal: an addition to the Goodsall's rule
}

\author{
Venkiteswaran Muralidhar, Santhaseelan R G, Ashwini Krishnamurthy
}

General Surgery, Sree Balaji Medical College and Hospital, Chennai, Tamil Nadu, India

\section{Correspondence to} Venkiteswaran Muralidhar, murlidharv@gmail.com

Accepted 25 September 2018

\section{DESCRIPTION}

Goodsall's rule (GR) states that if the external opening of an anal fistula is anterior to a transverse line across the anus will open radially into the anterior wall of the anal canal provided it is less than $3 \mathrm{~cm}$ from the anal verge, else it will open in

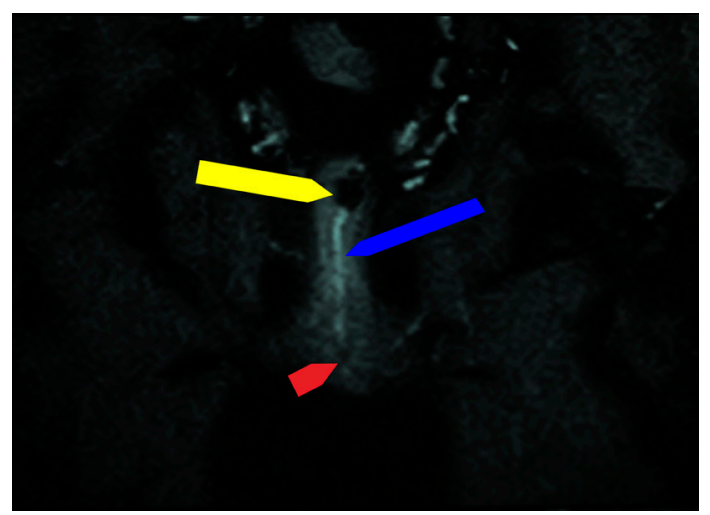

Figure 1 MRI fistulogram STIR coronal view showing the fistulous tract (blue arrow), external opening in the scrotal midline raphe (yellow arrow) and anal verge (short red arrow). STIR, Short-TI Inversion Recovery.

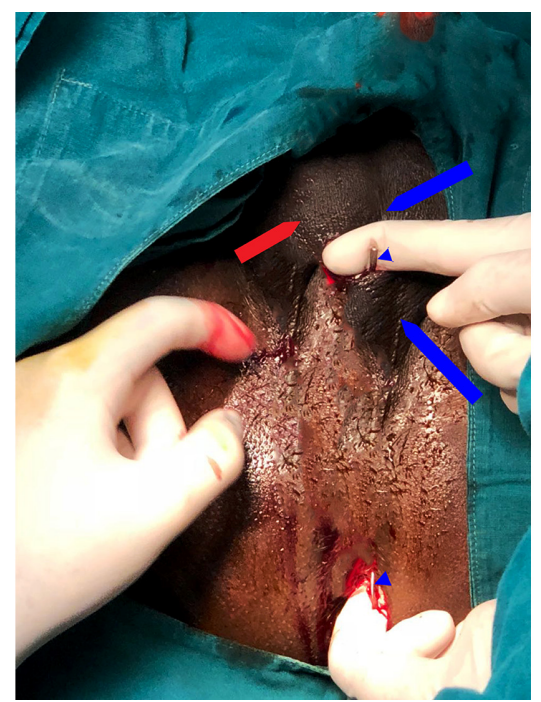

Figure 2 Intraoperative photo showing the long anterior low anal fistulous track. The left index finger is in within the anal canal, the metal probe (blue arrow heads), median scrotal raphe (blue arrows) and the right testis (red arrow) are also seen. the midline posteriorly. ${ }^{1}$ Exceptions to this rule have been reported for long anterior fistulas which instead of opening posteriorly in the midline as per the GR, opens anteriorly. ${ }^{2}$ There is one report of a rare case of a low anal fistula with two external openings on the midline raphe which opened radially in the anterior wall of the anal canal at 12 o'clock. ${ }^{3}$ In a recent review of a large series of high anterior anal fistulas opening in the scrotum, it was pointed out that long anterior anal fistulas are an exception to the GR. Nearly $90 \%$ of anal fistulas with scrotal openings had an anterior internal opening. In this series of 48 cases, there is a solitary case of an external opening in the midline raphe. This case is a low trans-sphincteric fistula opening anteriorly but the exact location of the internal opening, as to whether it opened radially at 12 o'clock, is not recorded. The authors conjectured

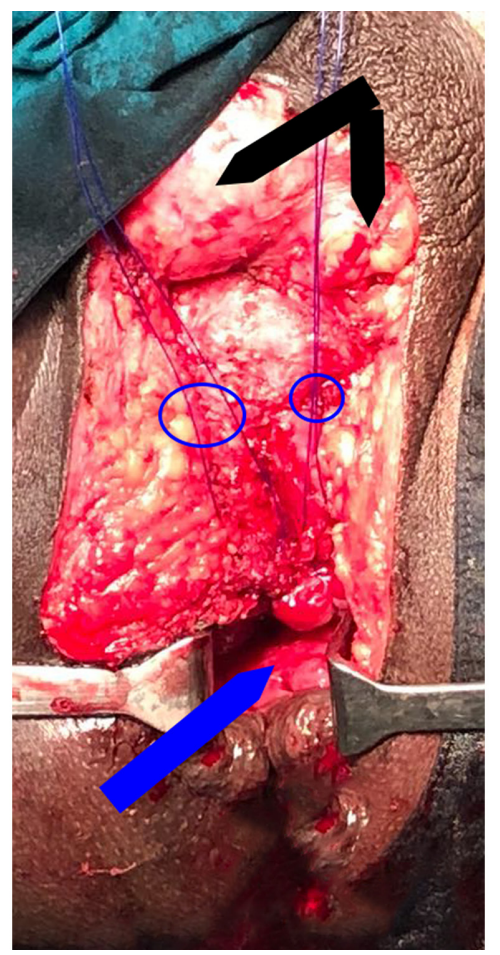

Figure 3 Intraoperative photograph after excision of the long low anterior fistulous track. The testis is marked by a black arrow, the polypropylene seton around the two high suprasphincteric extensions (blue circles) and the anal opening is shown with a blue arrow. 


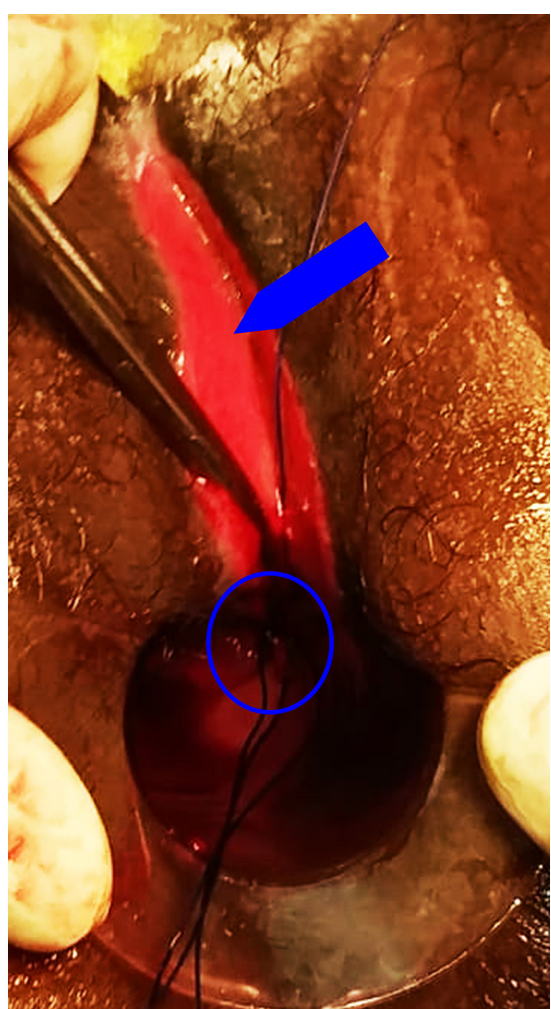

Figure 4 The postoperative wound after 1 month with the partially healing wound of the low anterior fistula (blue arrow) and the two seton sutures after tightening (blue circle).

that all exceptions of the GR, wherein a long anterior fistula opening anteriorly will possibly be of a low variety, either intersphincteric or trans-sphincteric. In their series, there was no case of long anterior high suprasphincteric fistulas with anterior internal openings. ${ }^{1}$ Taken together, the above shows that anal fistulas opening in the midline raphe of the scrotum are rarely reported, are primarily of the low variety with no suprasphincteric extensions and open anteriorly in the anal canal.

We hereby report a case of a complex fistula-in-ano which has both a low and a high suprasphincteric element that opens radially from the external opening in the midline raphe into the anal canal. A 35-year-old man, with a chronic discharging fistula, opening externally in the median raphe of the scrotum reported to the department of a major teaching hospital. He had been having discharge and pruritus for the past 6 months, and he has not been on any medication. He gives no history of perianal abscess, anorectal bleeding or painful defecation. He has no history suggestive of inflammatory bowel disease, tuberculosis or sexually transmittable disease. He is non-diabetic and non-hypertensive. On clinical examination, he had an anal fistulous opening situated $15 \mathrm{~cm}$ from the anal verge in the midline to the scrotal midline raphe. Per rectal examination showed an internal opening at the dentate line at 12 o'clock position. This was confirmed by MRI and also by probing under anaesthesia (figures 1 and 2). The MRI also showed two suprasphincteric extensions. The low fistulous tract was excised. The high fistulas were treated by the seton method using number 1 monofilament polypropylene suture 1 (figure 3 ). The seton was tightened at biweekly intervals, one of the setons was removed in the third sitting and the second one at the fourth sitting after 2 months (figures 4 and 5). The wound healed fully in 3 months, and

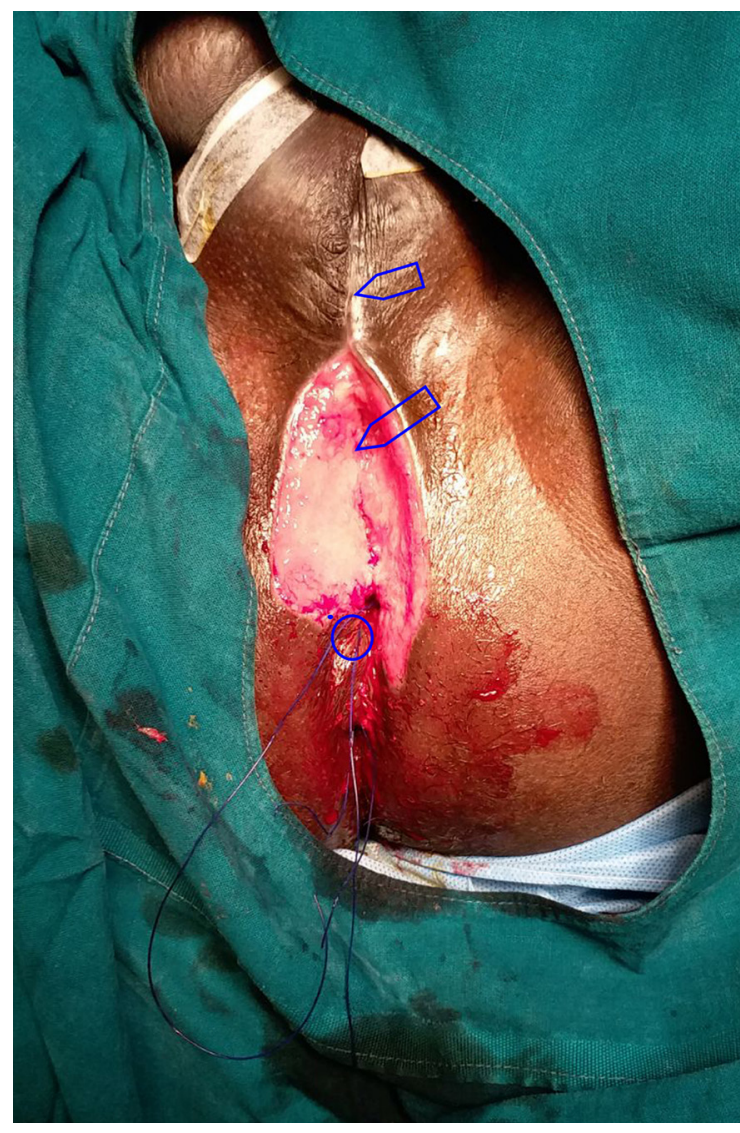

Figure 5 The postoperative wound after 2 months with the partially healing wound of the low anterior fistula (blue arrow) and the two seton sutures after tightening (blue circle).

currently the patient is asymptomatic and has full continence at 6 months of follow-up.

According to the best of our knowledge, this is the first reported case of a mixed anal fistula (with high and low components) wherein, the low component opened in the midline raphe of the scrotum that had a corresponding internal opening radially in the anal canal. The other two similar cases reported openings in the midline scrotal raphe were low anal fistulas. ${ }^{13}$ Hence, we propose an addition, rather than an exception to the GR rule by stating that long anterior fistulas with midline external openings in the medical scrotal raphe could have a corresponding internal opening at a radial location at 12 o'clock, irrespective of whether they also have a high suprasphincteric component.

\section{Learning points}

- Long anal fistulas opening in the midline raphe of the scrotum have a corresponding radial opening at 12 o'clock in the anal canal.

- An addition to the Goodsall's rule is that long low anterior fistulas in the midline raphe of the scrotum also open radially like the short anal fistulas (less than $3 \mathrm{~cm}$ from the anal verge).

- This addition to the Goodsall's rule is irrespective of whether or not the anal fistula also has a high suprasphincteric extension. 
Contributors VM and SRG diagnosed the case, planned the treatment and performed surgery and postoperative care. VM wrote the manuscript. AK looked up references.

Funding The authors have not declared a specific grant for this research from any funding agency in the public, commercial or not-for-profit sectors.

Competing interests None declared.

Patient consent Obtained.
Provenance and peer review Not commissioned; externally peer reviewed.

\section{REFERENCES}

1 Araki Y, Kagawa R, Yasui $H$, et al. Rules for anal fistulas with scrotal extension. J Anus Rectum Colon 2017;1:22-8.

2 Abou-Zeid AA. Anal fistula: intraoperative difficulties and unexpected findings. World J Gastroenterol 2011;17:3272-6.

3 Shindhe PS, rare Mof. low anal anterior fistula exception to Goodsall's rule with Ksharasutra. Ancient Science of Life 2014;33:182-5.

Copyright 2018 BMJ Publishing Group. All rights reserved. For permission to reuse any of this content visit

http://group.bmj.com/group/rights-licensing/permissions.

BMJ Case Report Fellows may re-use this article for personal use and teaching without any further permission.

Become a Fellow of BMJ Case Reports today and you can:

- Submit as many cases as you like

- Enjoy fast sympathetic peer review and rapid publication of accepted articles

- Access all the published articles

- Re-use any of the published material for personal use and teaching without further permission

For information on Institutional Fellowships contact consortiasales@bmjgroup.com

Visit casereports.bmj.com for more articles like this and to become a Fellow 